\title{
Public Health and the 21st Century Health Care System: No One Can Left Behind
}

\author{
Tahmina Afrose \\ Community Medicine Department, Faculty of Medicine, AIMST University, Bedong, Malaysia
}

\section{Email address:}

drafrosekeya@gmail.com

\section{To cite this article:}

Tahmina Afrose. Public Health and the 21st Century Health Care System: No One Can Left Behind. Journal of Family Medicine and Health Care. Vol. 3, No. 2, 2017, pp. 30-35. doi: 10.11648/j.jfmhc.20170302.11

Received: June 5, 2017; Accepted: August 16, 2017; Published: September 6, 2017

\begin{abstract}
The global health architecture is more extensive but very complex. The boundaries of public health are now integrating with other sectors. Now a day's globalization and urbanization are playing the key roles. Developing countries are bearing the greatest burden from the chronic diseases. Emerging diseases having greater influences on the economies. Sufficient skilled health workers are the requirements. Health challenges require active involvement of all levels of government. It is required to act together to overcome those health challenges now and to face an uncertain environment in future.
\end{abstract}

Keywords: Public Health, Evidence Based, Essential Public Health Services, Global Health, Population Ageing, Healthy People 2020

\section{Introduction}

Through surveillance system public health contributing in improving the health and quality of life by preventive and treatment approaches. For better health outcomes its activity includes assessing and evaluating the current services of the health care system, meeting the requirements of the stakeholders, selecting the appropriate interventions, costeffective resource allocation, planning, educating and empowering people about the health issues. [1, 2, 3, 4]

Now a days the health care system is market-oriented which is a technology-based entrepreneurial free market that giving the opportunity of higher quality of services at a lower costs. Health transformation is now a necessity. The Challenges are the homeland security, population aging, and medical negligence, the increasing chronic and noncommunicable diseases, less health care providers, unsustainable increase in costs of health care services and the disparities. The elimination of health disparities and an affordable access to quality care for the poorest must be a critical goal for now and the upcoming future. [5, 6]

\section{Role of Public Health on Healthcare}

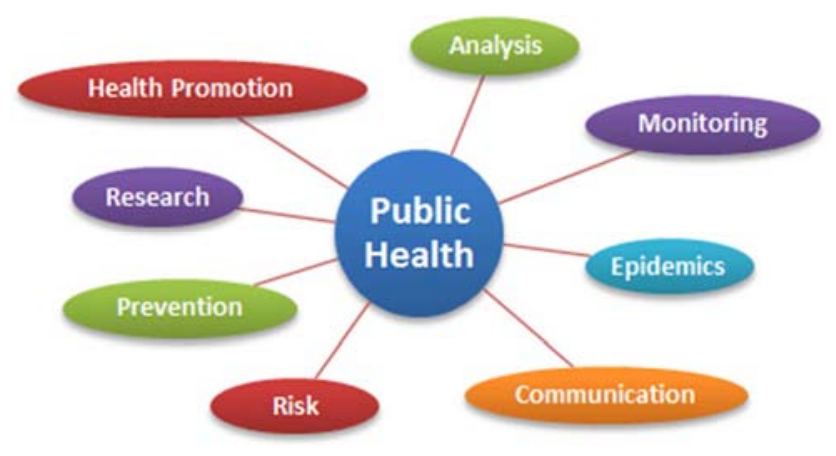

Figure 1. Role of Public Health.

Public Health plays the key role (Figure 1) for assessing and identifying the population needs such as: $[7,8,9,10]$

1. Assessing and evaluating the current services of the health care system.

2. Identifying the needs.

3. Setting the most appropriate goal, strategies and interventions based on health care needs.

4. Informing, educating and empowering the people about the health issues. 


\section{Public Health Framework}

Public Health Framework includes different types of activities that can be categorized into the following areas:

(1) Evidence Base: The three interrelated key components are (Figure 2) the research, surveillance and epidemiology and community consultation. [11]

(2) Risk Assessment: It includes the following steps (Figure 3):
a. Hazard identification
b. Hazard Characterization
c. Exposure Assessment
d. Risk Characterization

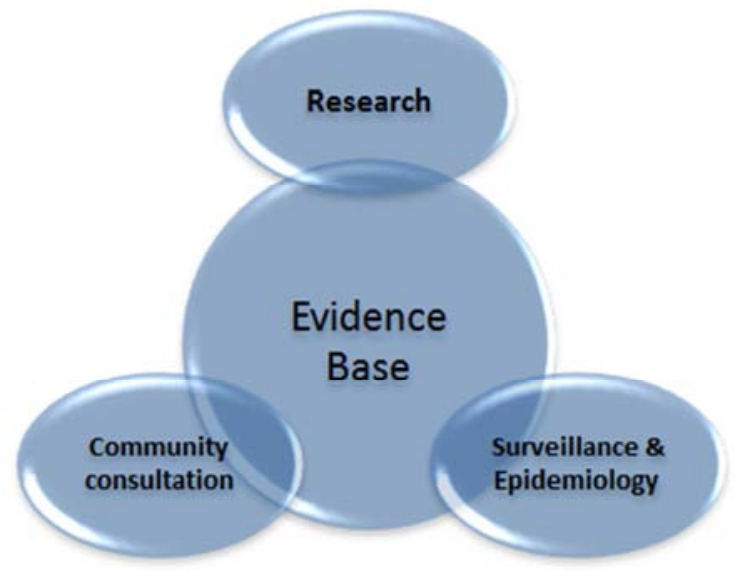

Figure 2. Key components of the Evidence Base.

\section{Hazard
Hentification Characterization Exposure Assessment $>$ Risk Characterization}

Figure 3. Components of the Risk Assessment.

(3) Policy: It requires the following interventions (Figure 4): [12]

a. Health Protection

b. Health Promotion and

c. Emergency Preparedness

(4) Evaluation: Evaluation of every policy and programs are required to evaluated by [13]:

a. output measures

b. outcome measures

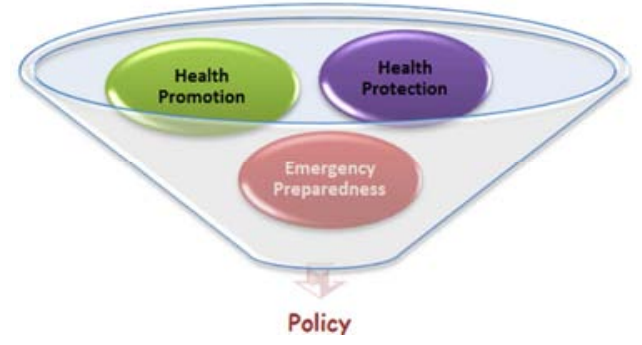

Figure 4. Interventions for policy development.

\section{Dimensions of Public Health System}

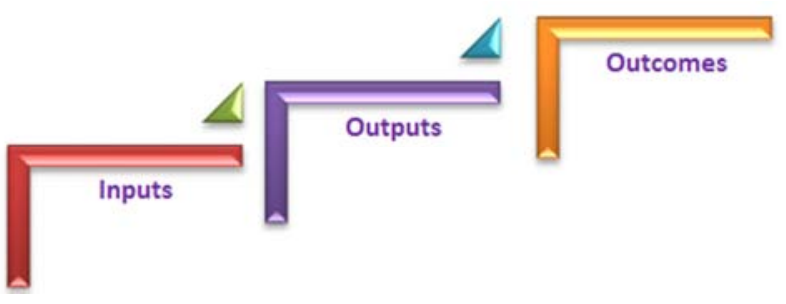

Figure 5. Dimensions of Public Health System.

To carry out the core function of the Public Health System the Basic requirements (Figure 5) are:

(1) Inputs: the resources.

(2) Outputs: the process that is required for an effective Health Care System.

(3) Outcomes: such as indicator of health status, risk reduction and quality of life.

\section{Essential Public Health Services}

To achieve the vision and mission of Public Health the following activities (Figure 6) are essential to carry out:

(1) Monitoring health status in the community

(2) Community diagnosis of health problem and health hazards

(3) Empowering people by proper training

(4) Community mobilization

(5) Developing policy and plans for individual and community health efforts

(6) Enforcing law and regulation for health safety

(7) Collaboration and Community participations

(8) Effective workforce

(9) Evaluation

(10) Research

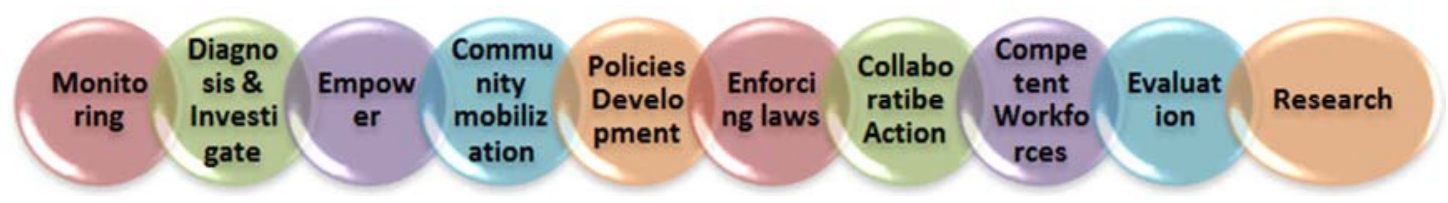

Figure 6. Essential Public Health care Services.

\section{The Essential Public Health Services}

The essential services of the public health should be (figure-7): 

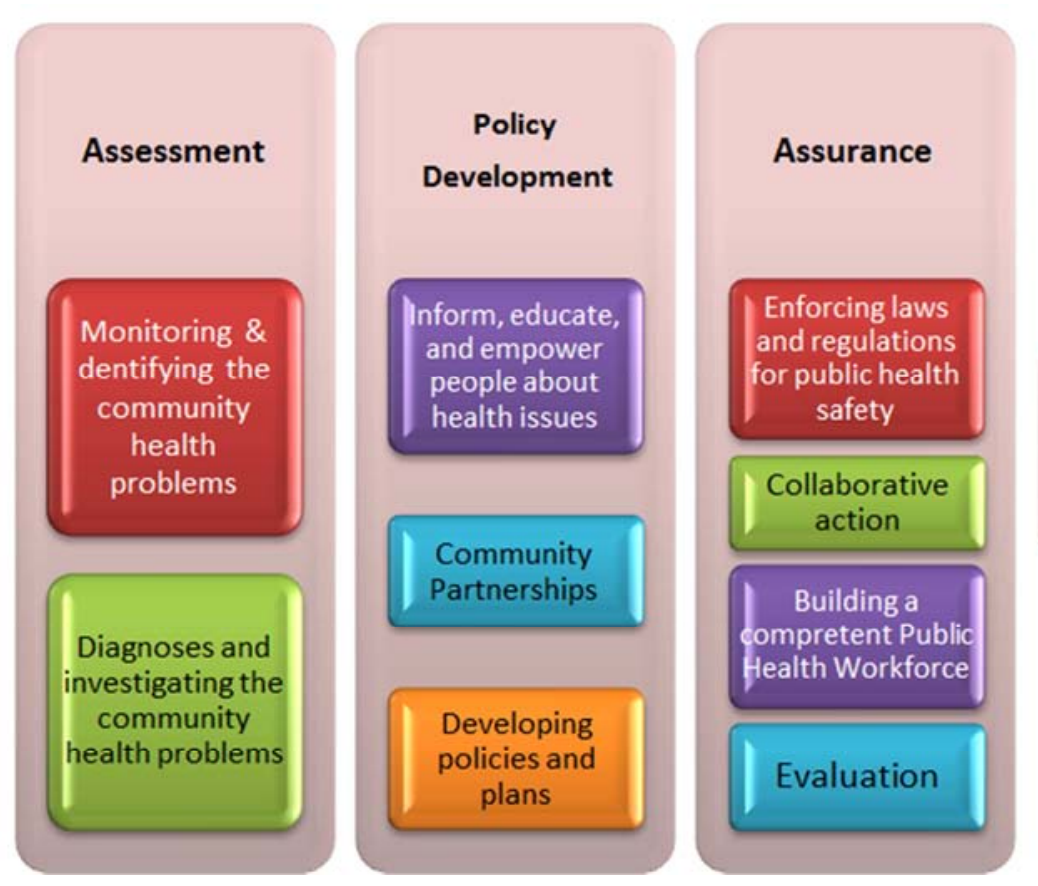

Figure 7. Essential Public Health Services.

\section{Concept of Global Health}

Global Health is defined as: "The area of study, research and practice that places a priority on improving health and achieving equity in health for all people worldwide". [14]

\section{Major Health Indicators}

(1) Mortality-Based Indicators:
a. Crude Mortality
b. Age-Specific mortality
c. Age-Adjusted mortality
d. Years of potential life loss (YPLL)

(2) Morbidity, Disability and Quality Indicators

a. Disability-Adjusted life-year(DALY)

b. Span-of-healthy-life-indicators(Years of Healthy Life)

\section{Ways to Healthy People: 2020}

To achieve better health outcomes by 2020 the U.S. Department of Health and Human Services (HHS) in collaboration with other federal agencies, stakeholders and the advisory committee set their vision, mission and goals [15] which has been summarized in the Table 1, can be an effective guideline for other countries as well.

Table 1. Healthy People 2020: Vision, Mission and Goals.

\section{Vision}

A society in which all people live long, healthy lives

Mission-Healthy People 2020 strives to:

Identify nationwide health improvement priorities;

Increase public awareness and understanding of the determinants of health, disease, and disability and the opportunities for progress;
Provide measurable objectives and goals that are applicable at the national, state, and local levels;

Engage multiple sectors to take actions to strengthen policies and improve practices that are driven by the best available evidence and knowledge; and Identify critical research, evaluation, and data collection needs

Overarching Goals

Attain high-quality, longer lives free of preventable disease, disability, injury, and premature death.

Achieve health equity, eliminate disparities, and improve the health of all groups.

Create social and physical environments that promote good health for all. Promote quality of life, healthy development, and healthy behaviors across all life stages.

\section{Measures towards Healthy People 2020 Goals}

The Table 2 illustrates the measures towards Healthy People 2020 goals which include General Health Status, Health-Related Quality of Life (HRQoL) and Well-Being, Determinants of Health and Disparities. [16]

Table 2. Measures towards Healthy People 2020 Goals.

\begin{tabular}{l}
\hline General Health Status \\
Life expectancy (With International Comparison) \\
Healthy Life Expectancy \\
Years of Potential Life Lost (YPLL) (With International Comparison) \\
Physically and Mentally Unhealthy Days \\
Self-Assessed Health Status \\
Limitation of Activities \\
Chronic Disease Prevalence \\
Health-Related Quality of Life (HRQoL) and Well-Being \\
Patient Reported Outcome Measurement Information System (PROMIS) \\
Global Health Measure \\
Well-Being Measures \\
Participation Measures \\
Determinants of Health
\end{tabular}




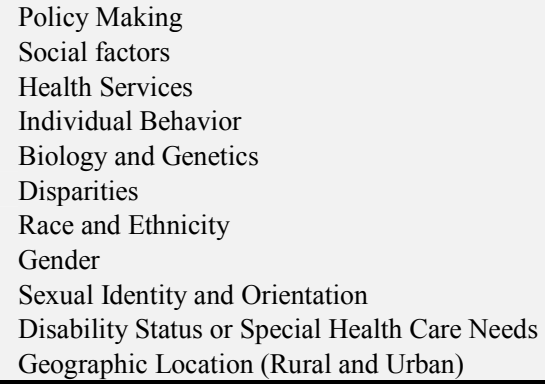

\section{Population Ageing: Why Matters}

Older people in all countries are a vital resource to their families and the communities. Rapid ageing in both develop and the developing countries has shown the significant changes in the following aspects:

(1) In the family structures

(2) In labor patterns

(3) In migration

(4) Pensions will need to cover a longer period of life.

(5) Health care costs will rise

Due to involvement of more women in formal workforce, fewer people are available to take care of the older people. Increase in the global average life expectancy, decreasing the fertility rates and the overall improvement of the medical care services are the key issues for the rapid population aging.

As we enter the process of globalization, ageing will put increased economic and social demands on both in developing and the developed countries. $[17,18]$

\section{Government's Role on Public Health}

Government is the prime and major responsible bodies. The areas are $[19,20]$ :

(1) Assuring an adequate local public health infrastructure,

(2) Promoting healthy communities and healthy behaviors,

(3) Preventing the spread of communicable disease,

(4) Protecting against environmental health hazards,

(5) Preparing for and responding to emergencies,

(6) Assuring quality health services by

(7) Accountability and credibility

(8) Adequate Resources allocation

(9) Transparency

(10) Efficiency and effectiveness.

(11) Research.

\section{Health Services Pyramid and level of Prevention of Disease}

Modern concepts of disease management has given more concerns on more integrated approach for better health outcomes and cost reduction. Treatment plans are based on proven interventions, increasing coordination, improving patient education and preventing avoidable medical complications.

Preventive intervention strategies are given at the primary, secondary and tertiary levels. The interventions under the primary prevention include Health promotion and Specific protection. Secondary prevention deals with early diagnosis and prompt treatment of diseases. Tertiary prevention has the intervention of disability limitation and the rehabilitation. Table 3 illustrates the Health care pyramid levels showing the relationship of the five intervention strategies to the three levels of preventions [21].

Table 3. Health Care Pyramid Levels.

Tertiary Medical Care (Required highly specialized personnel and
facilities)
Disability Limitation
Rehabilitation
Secondary Medical Care (Support services for people with special
challenges due to chronic or long term conditions)
Early diagnosis and Prompt treatment
Primary Medical Care (First-contact treatment services, clinical preventive
services and ongoing care for commonly encountered medical condition)
Health Promotion
Specific Protection
Population-Based Public Health Care Services (Community's overall
health profile)
Disease prevention
Health Promotion

Source: Hyattsville, PHS; US Public health Service. For a Healthy Nation: Return on Investments in Public Health, 1994.

It has been suggested that Health Services Pyramid (Figure 8) should be constructed from the bottom up manner where the medical services should be built on a foundation of population-based services. [22]

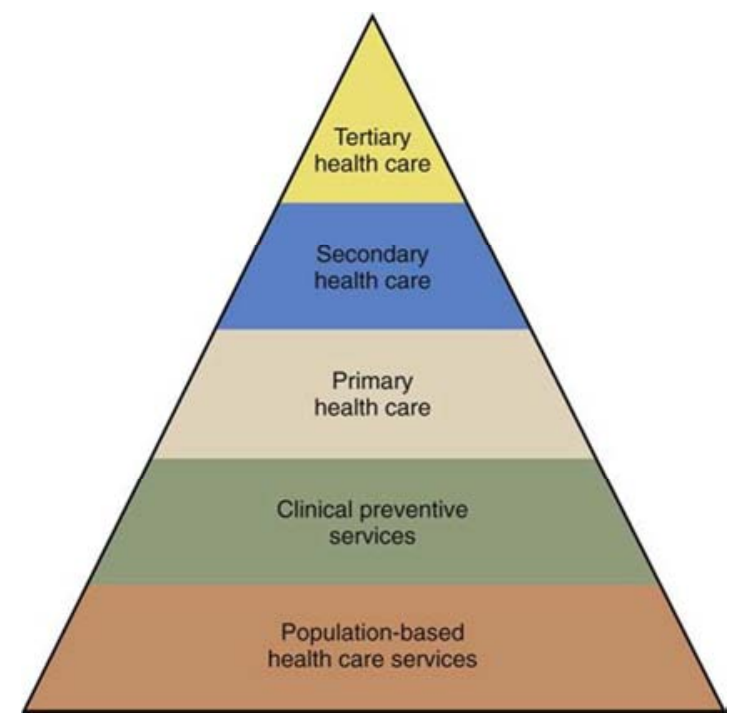

Figure 8. Health services pyramid.

\section{The Key Issues}

Gathering knowledge from previous history if we look forward the $21^{\text {st }}$ Century health care system should have: [5] 
(1) More Integrated approach

(2) More financial availability

(3) More accountability

(4) More awareness and responsible for the population needs

(5) Effective resources allocation

(6) More innovative towards health

(7) More inclusive

(8) For concerned on prevention rather than treatment

(9) More focused on the improvement of the entire population

(10) More evidence based

(11) Resiliency

\section{The Challenges}

Learning from the past Century It has been identified that the public's health care needs have been changed. In future due to advances in medical science and technology, aging population together with the incidence and prevalence of chronic conditions will be a major concern. The challenges are: $[5,23]$

(1) Reengineered care processes

(2) Effective use of information technologies

(3) Knowledge and skills management

(4) Development of effective teams

(5) Coordination of care across patient conditions, services, sites of care over time

\section{Ways to Look Forward}

For a better Health Care Delivery System Framework should be redesign for a better outcome by $21^{\text {st }}$ Century. The following aspect is required to give more concern: [23, 24, and 25]

(1) The health care system must be responsive at all times, and access to care should be provided by using information technology in addition to in-person visits.

(2) The Care should be design according to patient needs and values.

(3) The system should be able to give importance in patient preferences and should encourage shared decision making.

(4) Effective communication and sharing information between clinicians and patients.

(5) Evidence-based Decision is required which should be scientifically sound.

(6) Reducing risk and ensuring safety.

(7) Transparency.

(8) The system should anticipate patient needs.

(9) Effective resource allocation.

(10) Cooperation and coordination among clinicians.

(11) Both public and private sector should require to carefully reexamining their payment policies to remove barriers that impede quality improvement and build in stronger incentives for quality enhancement.

(12) Adequately preparing the workforce by providing more opportunities for interdisciplinary training, by modifying the ways in which health professionals are regulated and accredited and by using the liability system to support changes in care delivery system.

By using advanced technology it is the time to redesign the nation's health care delivery system. Better approaches are now a key issue to meeting the health care needs at every level.

\section{References}

[1] Gillam Stephen; Yates, Jan; Badrinath, Padmanabhan (2007). Essential Public Health: theory and practice. Cambridge University Press. OCLC 144228591.

[2] Pencheon, David; Guest, Charles; Melzer, David; Gray, JA Muir (2006). Pencheon, David, ed. Oxford Handbook of Public Health Practice. Oxford University Press. OCLC 663666786

[3] Smith, Sarah; Sinclair, Don; Raine, Rosalind; Reeves, Barnarby (2005). Health Care Evaluation. Understanding Public Health. Open University Press. OCLC 228171855.

[4] Sanderson, Colin J.; Gruen, Reinhold (2006). Analytical Models for Decision Making. Understanding Public Health. Open University Press. OCLC 182531015.

[5] Consumer Health: Collection Development Services for Public Libraries. Healthy People 2010. A Systematic Approach to Health Improvement.

[6] Hagist C, Kotlikoff LJ. Health Care Spending: What the Future Will Look Like. National Center for Policy Analysis; NCPA Policy Report No. 286, June 2006.

[7] Gillam Stephen; Yates, Jan; Badrinath, Padmanabhan (2007). Essential Public Health: theory and practice. Cambridge University Press. OCLC 144228591.

[8] Pencheon, David; Guest, Charles; Melzer, David; Gray, JA Muir (2006). Pencheon, David, ed. Oxford Handbook of Public Health Practice. Oxford University Press. OCLC 663666786

[9] Smith, Sarah; Sinclair, Don; Raine, Rosalind; Reeves, Barnarby (2005). Health Care Evaluation. Understanding Public Health. Open University Press. OCLC 228171855.

[10] Sanderson, Colin J.; Gruen, Reinhold (2006). Analytical Models for Decision Making. Understanding Public Health. Open University Press. OCLC 182531015.

[11] Brownson RC, Fielding JE, Maylahn CM 2009. Evidencebased public health: A fundamental concept for public health practice. Annu. Rev. Public Health 30: 17-201.

[12] The Association of Faculties of Medicine in Canada. The stages of prevention. Accessed January 21, 2015.

[13] Centers for Disease Control and Prevention. Introduction to program evaluation for public health programs: A self-study guide. 2012. Accessed December 10, 2014.

[14] Koplan JP, Bond TC, Merson MH, et al. (June 2009). "Towards a common definition of global health". Lancet. 373 (9679): 1993-5. doi:10.1016/S0140-6736(09)60332-9. PMID 19493564. 
[15] US Department of Health and Human Services, Healthy People 2020 Framework, March 15, 2014.

[16] US Department of Health and Human Services, Healthy People 2020 Framework, June 3, 2014.

[17] Why Population Aging Matters Global Perspective. 2007. National Institute on Aging National Institute of Health U.S. Department of Health and Human Services U.S. Department of State, pp. 6-7.

[18] World Population Ageing: 1950-2050. 2002. United Nations Population Division (UNPD), p.11.

[19] CHS Administration Handbook, Government's Responsibility for Public Health, Minnesota's Public Health System, January 2014.

[20] National Public Health Standards and Voluntary Accreditation: Implications and Opportunities for Public Health Performance Improvement in Minnesota (PDF: 725KB / 56 pages.
[21] Hyattsville, PHS; US Public health Service. For a Healthy Nation: Return on Investments in Public Health, 1994.

[22] US Public Health Service: The core functions project, Washington, DC, 1994/update 2000, Office of Disease Prevention and Health Promotion.

[23] US Department of Health and Human Services, Healthy People 2020 Framework, March 15, 2014.

[24] The world health report 2006 - working together for health. Geneva: WHO; 2006.

http://www.who.int/bulletin/volumes/85/12/07-046110/en/

[25] Kass NE. Public health ethics: from foundations and frameworks to justice and global public health. J Law Med Ethics 2004; 32: 232-8 doi: $10.1111 / \mathrm{j} .1748$ 720X.2004.tb00470.x pmid: 15301188. 